\section{Brexit and shortages}

\author{
Pascal Garel
}

On 29 March 2017, the United Kingdom (UK) submitted the notification of its intention to withdraw from the European Union (EU). This means that unless a ratified withdrawal agreement establishes another date, all EU primary and secondary law ceases to apply to the UK from 30 March 2019 and the UK becomes a 'third country'.

The regulation of goods is managed by EU-wide systems, facilitating trade under the single market. This means that products are regulated to make sure that they are safe before they can be placed on the EU market. They are also closely monitored after being placed on the market to ensure continued safety. Any changes to this regime may have an impact on supplies across Europe.

Subject to any transitional arrangement in a possible withdrawal agreement, the EU rules in the field of medicinal products for human and veterinary use will no longer apply to the UK. This has, in particular, the following consequences in the different areas of EU law on medicinal products: EU law requires that marketing authorisation holders are established in the EU (or European Economic Area (EEA)): some activities must be performed in the EU (or EEA), related for example to pharmacovigilance, batch release and quality control.

Every month, 45 million packs of medicine go from the UK to Europe-and over 37 million packs come back the other way. Without clarity on customs arrangements, medicines regulation or whether there will be a transition period, this essential planning is taking priority over research and development.

Correspondence to Pascal Garel, European Hospital and Healthcare Federation (HOPE), Bruxelles 1000, Belgium; sg@hope.be
The link between stockpiling and shortages is fairly well documented. An actual shortage triggers stockpiling activity that exacerbates the shortage and prevents proper management. There have also been reports in the past of stockpiling being used as a mechanism to exacerbate a shortage and influence pricing.

On 10 July 2018, the European Medicines Agency (EMA) published a press release that presented the gaps in industry preparedness for Brexit. The survey indicates that some companies need to step up efforts to ensure medicine supply in the EU.

The survey was looking at the Brexit preparedness plans of marketing authorisation holders who have centrally authorised medicinal products located in the UK. The survey aimed to identify centrally authorised products that are potentially at risk of supply shortages, to assess how critical these are and discuss relevant mitigation measures.

The survey shows that marketing authorisation holders for more than half $(58 \%)$ of the 694 centrally authorised products, with an important step in their regulatory processes in the UK, are on track with their regulatory planning to ensure that their marketing authorisation remains valid once the UK leaves the EU.

However, for 108 (88 human products and 20 veterinary products), or $16 \%$, of these medicines with manufacturing sites located in the UK only, there are serious concerns that the necessary actions will not be carried out in time. For $10 \%$ of the products included in the survey, the EMA received no feedback from companies.

As the EU and the UK do not seem to move, arrangements for the regulation of medicines and medical devices need be addressed as a matter of urgency.
The Brexit Health Alliance is wisely calling for:

- 'Future cooperation on medical devices and medicines to be prioritised in the negotiations, so that patients and the wider public are not negatively impacted from disruptions in the supply of medicines and other health technologies, or from a reduction in standards or safety;

- Patient safety and public health to be guaranteed post-Brexit through aligning the UK as much as possible with the EU's regulation of medicines and medical devices, and by close regulatory cooperation between the EU and UK, as proposed by the UK government;

- Pragmatic solutions allowing patients and the public to benefit from the UK's participation in EU systems such as data-sharing networks, pharmacovigilance and the new clinical trials infrastructures post-Brexit;

- An implementation period beyond the twoyears of Article 50 negotiations (which end in March 2019) should adequately reflect the time needed to ensure relevant customs, trade and regulatory procedures are in place. ${ }^{\mathrm{i}}$

Competing interests None declared.

Provenance and peer review Commissioned; internally peer reviewed.

(c) European Association of Hospital Pharmacists 2018. No commercial re-use. See rights and permissions. Published by BMJ.

$$
\text { (D) Check for updates }
$$

To cite Garel P. Eur J Hosp Pharm 2018;25:291.

Published Online First 2018

Eur J Hosp Pharm 2018;25:291.

doi:10.1136/ejhpharm-2018-001739

${ }^{i}$ https://www.nhsconfed.org/regions-and-eu/nhseuropean-office/brexit/brexit-health-alliance/ access-to-medicines-and-medical-technologies 